\title{
RUPTURE OF THE INTERVENTRICULAR SEPTUM IN MYOCARDIAL INFARCTION
}

\author{
BY \\ W. M. PHILIP \\ From Selly Oak Hospital, Birmingham
}

The number of cases in which the diagnosis of perforation of the interventricular septum due to myocardial infarction has been made during life is still below 40. Evans and Anderson (1952) have recently reported three cases: others have been reported by Black (1952), Zucker et al. (1952), and Salomon and Gross (1952). The first case was reported by Latham (1845).

\section{Case Report}

A man, aged 67, was admitted to Selly Oak Hospital on 27/12/52. He had been short of breath and had had a cough for some years. He was not a good witness but he seemed to have been in reasonably good health until 15/12/52 when he was at work. On this day he felt so weak he could not stand up and had to be taken home from work; since then he had been in bed and had become progressively more dyspnœic. His cough was producing a certain amount of greenish sputum; there had been no hæmoptysis. He denied having had any pain in the chest but, on being pressed, admitted to having occasional pains in various situations which had been made worse by breathing. He had had double pneumonia in 1914.

On admission he was orthopnœic and slightly cyanosed. The veins in the neck were distended up to the angle of the jaw; there was no clubbing of the fingers. Sacral œedema was present. There was a blood pressure of $120 / 80$ and the heart was considerably enlarged. The pulse was regular. The apex beat could not be defined, but X-ray subsequently confirmed the cardiac enlargement. A systolic thrill could be felt over the lower end of the sternum and there was a systolic murmur in the same area; this murmur was well heard at the apex of the heart and could also be heard in the axilla. The murmur was also conducted upwards to the base of the heart, but could not be heard in the great vessels. The aortic second sound was almost inaudible but the pulmonary second sound was well heard. No diastolic murmur was heard. An electrocardiogram showed evidence of a recent posterior infarct (Fig. 1) and a diagnosis of perforated interventricular septum due to infarction was made.

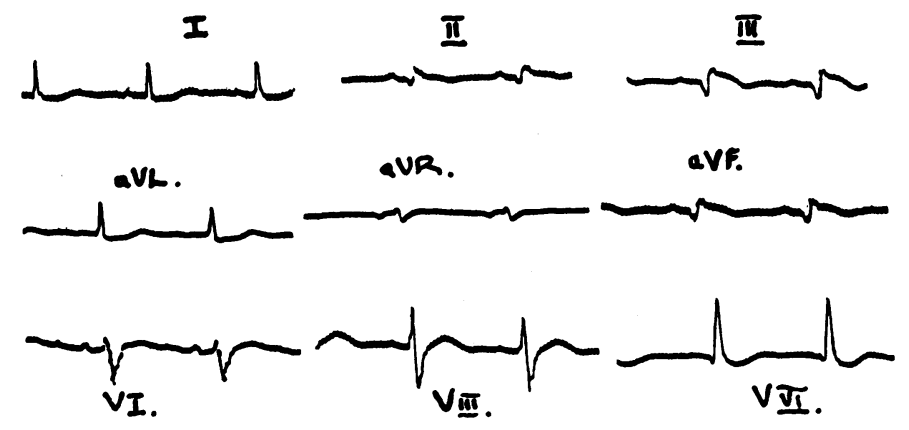

FiG.-Electrocardiogram showing recent posterior cardiac infarction.

The chest was emphysematous and scattered rhonchi and crepitations were present. The liver was enlarged and the firm edge could be felt about $5 \mathrm{~cm}$. below the costal margin. On two occasions it was considered that pulsation was present but no pulsation was seen in the veins in the neck. The spleen was not palpable. The urine contained no albumin or sugar and the centrifuged deposit was normal. During the next fortnight he steadily deteriorated; the liver became even more enlarged and he eventually died. 


\section{Necropsy Report}

Thorax. There were dense adhesions over both lower lobes. The pericardium was normal. An area of thinning was present in the posterior wall of the left ventricle. This area seemed to have been the site of a previous infarct with subsequent fibrosis. On top of this there had been a recent infarction. A small part of the posterior region of the interventricular septum was involved, and through this area there was a rupture which involved the fibrosed tissue, with no obvious indication as to the age of the rupture (Fig. 2). There was

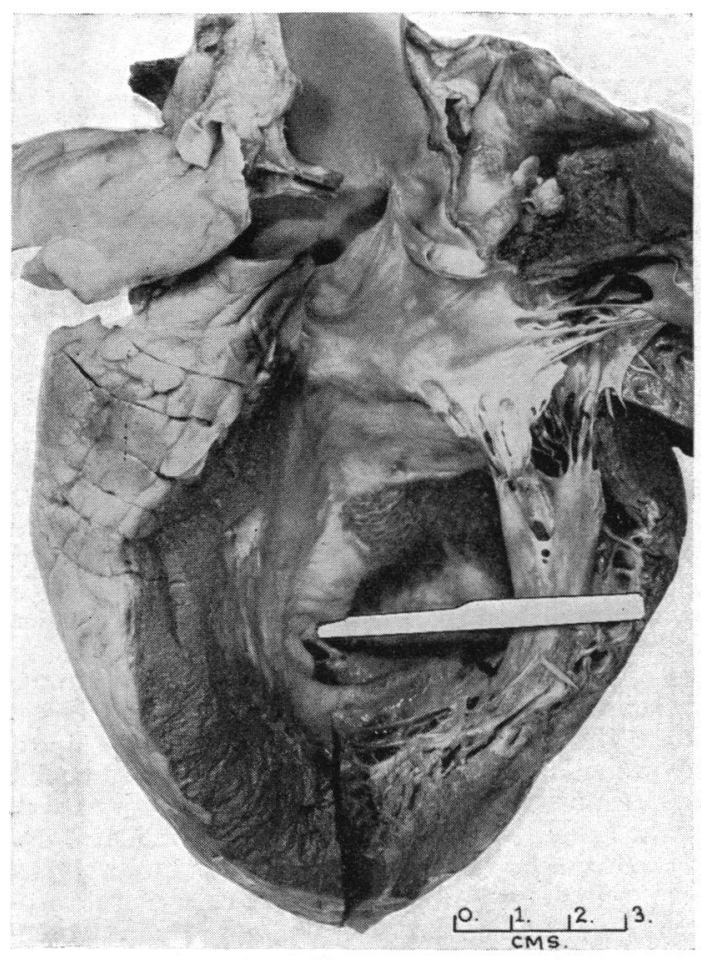

A

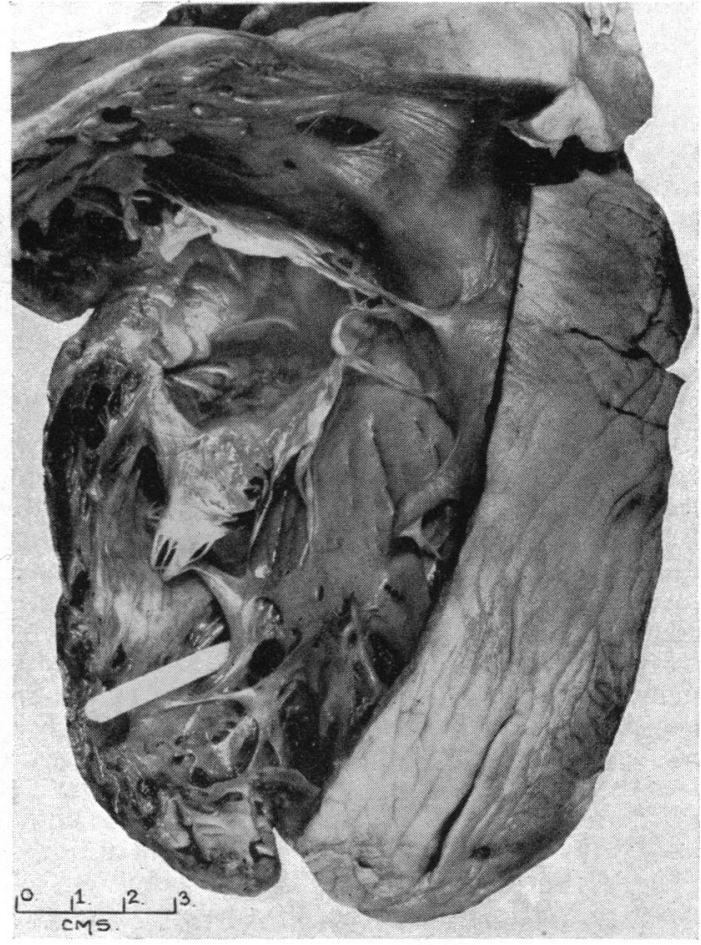

B

FIG. 2.-(A) Photograph showing cavity of left ventricle: white rod through perforation in interventricular septum. Infarcted area visible above. (B) Photograph showing cavity of right ventricle and septal perforation.

slight hypertrophy of the left ventricle but more marked hypertrophy of the right. Both mitral and tricuspid valve rings were dilated but no other valvular abnormality was present. There was a recent thrombosis in the right coronary artery; this appeared to involve an area where there had been partial occlusion of some standing; other arteries are patent. The lungs were œdematous but appeared normal otherwise.

Abdomen. The liver was much congested and the gall bladder and stomach and intestines were normal. The spleen was slightly congested. Suprarenals were normal, as were the kidneys, apart from congestion.

Sections. Sections of the right lung showed thickening of the interlobar septum between the middle and the lower lobes and fibrosis of adjacent interalveolar septa. The liver and spleen showed congestion while the liver and kidneys showed parenchymatous degeneration.

\section{Discussion}

Muller et al. (1950) who reported a case in which the diagnosis was confirmed by cardiac catheterization, and latter at necropsy, indicated three points in the diagnosis of their case.

(i) The development of the loud systolic murmur between the apex and lower end of the sternum.

(ii) Cardiographic evidence of right-sided dilatation or right bundle branch block.

(iii) Gross right-sided heart failure following myocardial infarction. 
But for the thrill, the diagnosis of perforated septum would probably not have been entertained in the present case. The thrill was situated lower down than that commonly found in congenital defects and when taken in conjunction with the electrocardiographic evidence of a recent infarct it seemed reasonable to associate the two findings. The third feature-severe right-sided failure-was also present.

\section{Summary}

A case is described in which myocardial infarction affected the posterior wall of the left ventricle and caused perforation of the interventricular septum. Observation of a systolic murmur and thrill at the lower end of the sternum with evidence of myocardial infarction led to the diagnosis being made during life.

I am indebted to Dr. J. S. McKinnell for the necropsy report, and to Mr. G. Holland for the photographs.

\section{REFERENCES}

Black, A. B. (1952). Brit. Heart J., 14, 288.

Evans, B., and Anderson, W. F. (1952). Brit. Heart J., 14, 537.

Latham, P. M. (1845). Lectures on Subjects connected with Clinical Medicine comprising Diseases of the Heart. London: Longmans, Brown, Green \& Longmans.

Muller, O., Humerfelt, S., Rasmussen, H., and Storstein, O. (1950). Acta Cardiologica, 5, 633.

Salomon, S., and Gross, L. (1952). N.Y. St. J. Med., 52, 1317.

Zucker, R., Leibowitz, W., Brody, H., and Sussmann, R. M. (1952). Arch. intern. Med., 89, 899. 